\title{
Which nutrients may contribute to healthy aging? A systematic review
}

\author{
C.H.S. Ruxton ${ }^{1}$ and E. Derbyshire ${ }^{2}$ \\ ${ }^{1}$ Freelance Dietitian, Nutrition Communications, 26 East Road, Cupar, KY15 4HQ, UK and ${ }^{2}$ Freelance Nutritionist, 65 \\ Mayfair Avenue, Worcester Park, Surrey, UK
}

Ageing is a multi-faceted and inevitable process involving a decline in health and well-being which could be ameliorated by dietary modification including supplementation. While people are living longer, the additional years do not translate into extra time spent in good health ${ }^{(1)}$.

Randomised controlled trials (RCTs) from 2005-2015 were identified using systematic approaches and the Preferred Reporting Items for Systematic Reviews and Meta-Analyses (PRISMA) guidelines. Inclusion criteria were participants aged 50-60 y, markers of age-related change as defined by the National Institutes of Health, and healthy subjects at baseline except for 'mild' cognitive impairment. Thirty-four RCT were found that met the criteria, with 12 of these investigating the role of fatty acids and 22 considering intakes of micronutrients in relation to healthy ageing as summarised below with numbers of positive (+ve), negative (-ve) and neutral (0) findings:

\begin{tabular}{|c|c|c|c|}
\hline \multicolumn{2}{|c|}{ LCn3PUFA interventions } & \multicolumn{2}{|c|}{ Micronutrient interventions } \\
\hline Aging marker & Summary of results & Aging marker & Summary of results \\
\hline Telomere length & +ve (1) & Bone health & +ve (4), - ve (1), 0 (1) \\
\hline Brain/cognitive & +ve (4), 0 (3) & Joint/muscle & + ve $(2)$ \\
\hline Eye health/vision & + ve (2) & Cataract & $0(2)$ \\
\hline Heart disease risk & +ve (2) & Cognitive/mood & +ve (2), 0 (3) \\
\hline Protein synthesis & +ve (1) & Cancer risk & + ve $(2)$ \\
\hline \multirow[t]{3}{*}{ Immune function } & +ve (2) & Heart disease risk & +ve (2) \\
\hline & & Immune function & $0(2)$ \\
\hline & & Vitamin status & +ve (1) \\
\hline
\end{tabular}

Several RCTs reported statistically significant positive outcomes and only one study noted a potential detriment; an association with higher invasive breast cancer risk with vitamin D supplementation. There were promising results for certain nutrients. For example, increasing long-chain $n 3$ polyunsaturated fat (LCn3PUFA) intakes appeared to have a role in improving memory, reducing the risk of dry eye, depression scores and levels of leucocyte telomere oxidative stress, while supporting muscle protein synthesis. Folic acid and B12 supplementation were found to impact positively on cognitive function. Combinations of calcium and vitamin D supplementation appeared to be effective for bone fracture prevention. The role of vitamin $\mathrm{K}$, especially menaquinone-7, in supporting bone health is emerging and requires further investigation. Finally, multivitamin use may be associated with reduced total cancer risk and enhanced mood.

In conclusion, certain nutrients were found to be consistent with healthier ageing, particularly LCn3PUFA, calcium, vitamin D and perhaps vitamin $\mathrm{K}$. There is good evidence that older populations have inadequate intakes of LCn3PUFA and vitamin D. Given the limited data for several aging markers, further RCTs on elderly populations are required which should take into account baseline nutritional status.

This work was funded by the Health Supplements Information Service (www.hsis.org) which is supported by an unrestricted grant from the Proprietary Association of GB.

1. Ruxton CHS et al. (2015). J Hum Nutr Diet doi: 10.1111/jhn.12335.

2. Ruxton CHS (2011). The benefits of fish consumption. Nutr Bull 36: 6-19.

3. Bates B et al. (2014). National Diet and Nutrition Survey rolling programme years 1-4. London: FSA. 